\title{
Theoretical background for the creation of wear- resistant coatings at the carbo-vibro-arc hardening
}

\author{
Aleksandr Kolomeichenko ${ }^{1 *}$, Nikolay Titov $^{3}$, and Aleksey Kolomeichenko ${ }^{2}$ \\ ${ }^{1}$ State Research Center of the Russian Federation FSUE «NAMI», Russian Federation \\ ${ }^{2}$ Orel State University named after I.S. Turgenev, Russian Federation \\ ${ }^{3}$ Orel State Agrarian University named after N.V. Parakhin, Russian Federation
}

\begin{abstract}
The paper presents the results of theoretical studies that allow predicting the formation of wear-resistant coatings on the working surfaces of machine parts by the method of carbo-vibro-arc hardening (CVAH). Analytical regularities of electric field intensity formation by oscillating carbon electrode during carbo-vibro-arc hardening (CVAH) have been established; the maximum layer thickness of multicomponent paste, 2.1...2.5 $\mathrm{mm}$, which ensures stable electric arc combustion during CVAH, has been theoretically substantiated. With the increase of amplitude and frequency of oscillations of the carbon electrode, the electric field strength at CVAH decreases nonlinearly, but the thickness of the hardened layer of the multicomponent paste has the greatest influence on it. As a result, ceramicmetal coatings of high quality and integrity are formed on the hardened surfaces of parts. The testing of the obtained theoretical regularities has confirmed their reliability.
\end{abstract}

\section{Introduction}

To increase the wear resistance of machine parts it is promising to form metal-ceramic coatings on their working surfaces [1-7]. One of the modern methods of their obtaining is carbo-vibro-arc hardening (CVAH). The first stage of the CVAH includes the creation of a uniform layer of a multicomponent paste of a certain thickness on the surface to be hardened. Then, after the paste polymerization, it is melted using a vibrating carbon electrode. The process of metal-ceramic coating formation with high physical and mechanical properties and tribotechnical characteristics is realized due to electric arc combustion [8-14].

One of the important conditions for the formation of quality metal-ceramic coatings during the CVAH is the need to ensure stable combustion of the electric arc. At the same time, research in this direction has not yet been sufficiently completed. So far, theoretical laws of formation of the electric field intensity by oscillating coal electrode during the CVAH have not been established. This, in turn, restrains the creation of a mathematical model of the CVAH process.

\footnotetext{
* Corresponding author: kolom sasha@,inbox.ru
} 


\section{Materials and methods}

During formation of metal-ceramic coatings by the CVAH method a multicomponent paste was used containing $60 \%$ of ПР-HX17CP 4 powder, $30 \%$ of boron carbide, and the rest cryolite. In connection with the widespread use of aqueous PVA glue solution in the CVAH coating formation processes, this solution was selected as a binder in these studies $[8,9,11$, $12,14]$.

The process of forming the hardening metal-ceramic coatings was carried out on the vibro arc hardening installation (VAH-2) and consisted of two stages:

- uniform application of the paste on the samples made of alloyed steel $65 \mathrm{G}$ and its polymerization (temperature $80 \ldots 85^{\circ} \mathrm{C}$ );

- the paste melting.

\section{Theory / calculation}

In order to form high-quality coatings during the CVAH (carbo-vibro-arc hardening) it is necessary to have a stable burning electric arc between the carbon electrode and the hardened surface with the applied paste layer. This can be ensured by creating the intensity E of the electric field exceeding the minimum threshold value. In traditional vibro arc surfacing $E$ can be determined by the formula [15]:

$$
E=k_{E} \cdot \frac{U_{0}-U_{k}-U_{a}}{\sqrt[3]{a \cdot R^{2} S^{2}}}, \mathrm{~V} / \mathrm{mm}
$$

where $k_{E}$ - correction factor;

$U_{0}$ - supply voltage, $V$;

$U_{\kappa,} U_{a}$ - voltage losses at the cathode and anode, respectively, $\mathrm{V}$

$\left(U_{\kappa}+U_{a}=17 \ldots 19 \mathrm{~V}\right)$

$a$ - electrode acceleration, $\mathrm{mm} / \mathrm{s}^{2}$;

$R$ - resistance of the contact zone located between the electrode and the hardened surface, Ohm;

$S$ - micro roughness area in the contact zone of the electrode and the hardened surface, $\mathrm{mm}^{2}$.

However, dependence (1) does not take into account the placement of a paste layer between the carbon electrode and the hardened surface, which has a significant resistance [12]. Taking into account this fact, the condition of stable electric arc burning at the CVAH can be determined by the formula:

$$
E=\frac{\left(U_{0}-U_{\kappa}-U_{a}\right)}{\delta\left(1+k_{a} \sqrt[3]{a \cdot R^{2} S^{2}}\right)} \geq E_{3},
$$

where $\delta$ - thickness of hardened paste layer, $\mathrm{mm}$;

$k_{a}$ - coefficient taking into account the effect of electrode oscillations on the strength;

$E_{3}$ - the minimum value of electric field strength, which ensures stable arc combustion at the CVAH, $\mathrm{V} / \mathrm{mm}$.

The carried out research [12] found that the acceleration $a$ can be determined by the formula (3), resistance $R$ - by the formula (4), the area $S$ - by the formula (5):

$$
a=4 A \pi^{2} f^{2}=12300 \ldots .49300 \mathrm{~mm} / \mathrm{s}^{2},
$$

where $A$ - oscillation amplitude of the carbon electrode at the CVAH, $\mathrm{mm}$ $(A=0,5 \ldots 1,1 \mathrm{~mm})$; 
$f$ - oscillation frequency of the carbon electrode at the CVAH, $\mathrm{Hz}(f=25 \mathrm{~Hz}$ and $50 \mathrm{~Hz})$.

$$
R=k_{\delta} \delta^{5}, \mathrm{Ohm},
$$

where $k_{\delta}$ - coefficient $\left(k_{\delta}=28500 \mathrm{Ohm} / \mathrm{mm}^{5}\right)$.

$$
S=0,25 \pi D^{2}, \mathrm{~mm}^{2},
$$

where $D$ - electrode diameter, $\mathrm{mm}$.

In view of the above, expression (2) can be represented as:

$$
E=\frac{\left(U_{0}-U_{\kappa}-U_{a}\right)}{\delta\left(1+2,9 \cdot k_{a} \sqrt[3]{A \cdot f^{2} \cdot k_{\delta}^{2} \cdot \delta^{10} \cdot D^{4}}\right)} \geq E_{\Gamma}, \mathrm{V} / \mathrm{mm}
$$

The process of sustained combustion of the arc at the CVAH (carbo-vibro-arc hardening) can be conventionally divided into three phases:

- the first phase, in which in the process of interaction of the electrode with the hardened paste layer in the creation of a potential difference $U_{0}-U_{a}-U_{\kappa} \approx 32 \ldots 42 \mathrm{~V}$ there is an electric field between the electrode and the metal surface, which affects the paste layer and changes the value of its electrical resistance, resulting in an increase of conductivity, increasing current with a simultaneous decrease of resistance and voltage drop to the value $\mathrm{U} 3$, which starts the process of arc ignition;

- the second phase, in which there is a "thin" arc, the cross-section of which begins to increase, so that the resistance of the molten layer of the paste, placed between the carbon electrode and the hardened metal surface, decreases with a simultaneous reduction of the power supply voltage to $U g$, at which the combustion of the arc becomes stable;

- the third phase, in which the arc cross-section, the surfacing current and the $U g$ source voltages are stabilized at a certain level, after which the CVAH process begins.

Determination of the coefficient $k a$ in dependence (6) was carried out as follows:

1) samples with different thicknesses of hardened paste layer were prepared and after ignition and the beginning of stable arc combustion the voltage values and the maximum value $\delta_{0 \max }$ were recorded. Above this value the ignition and stable arc combustion could not be ensured. According to the obtained results, the corresponding values of tension $E_{3}$ were calculated:

$$
E_{3}=\frac{\left(U_{0}-U_{\kappa}-U_{a}\right)}{\delta_{0 \max }}, V / \mathrm{mm}
$$

2) then, taking into account dependence (7), for the specified values of $A, f$ and $D$, we calculated the mean values of $E_{3}$, the corresponding mean square deviations, coefficients of variation and values of the coefficient $k_{a}$ by the formula:

$$
k_{a}=0,345 \frac{\frac{\delta_{0 \max }}{\delta_{\max }}-1}{\left.\sqrt[3]{A \cdot f^{2} \cdot k_{\delta}^{2} \cdot \delta_{\max }^{10} \cdot D^{4}}\right)}
$$

As a result of the calculations, the average value of the coefficient $k_{a}$ was $10^{-6}$.

Analysis of the results of studies of the electric field $E_{\Gamma}$ intensity for the considered composition of multicomponent paste showed that the value of the $E_{\Gamma}$ practically does not depend on the ratio of the paste main components in the considered ranges of their variation. The mean square deviation and the coefficient of variation are, respectively, $\quad 0,26 \mathrm{~V} / \mathrm{mm}$ and $8,5 \%$, which is generally very insignificant.

Therefore, dependence (6) can be written: 


$$
E=k_{6} E_{0} \geq E_{\Gamma(\max )}=3,9 \mathrm{~V} / \mathrm{mm},
$$

where $k_{b}$ - coefficient, defined according to the formula:

$$
k_{6}=\left(1+2,9 \cdot k_{a} \sqrt[3]{A \cdot f^{2} \cdot k_{\delta}^{2} \cdot \delta^{10} \cdot D^{4}}\right)^{-1}
$$

$E_{0}$ - field strength at the non-oscillating electrode:

$$
E_{0}=\left(U_{0}-U_{\kappa}-U_{a}\right) / \delta, \mathrm{V} / \mathrm{mm}
$$

Graphical dependences of intensity $E$ on the thickness $\delta$ of the hardened paste layer at amplitudes and frequencies of oscillations of the carbon electrode, $\mathrm{A}=0.5 ; 1.1 \mathrm{~mm}$ and $f=$ $25 ; 50 \mathrm{~Hz}$, respectively, are shown in fig. 1 .

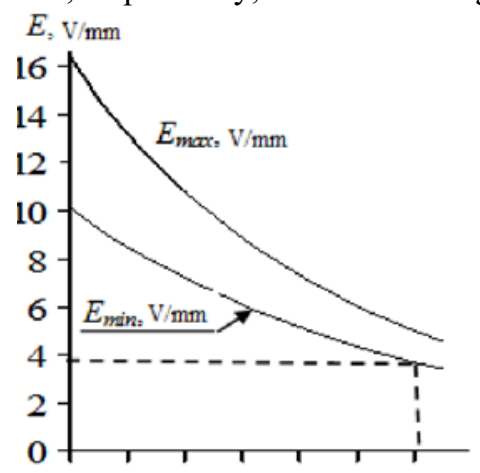

$1,61,822,22,42,6 \delta, \mathrm{mm}$

a)

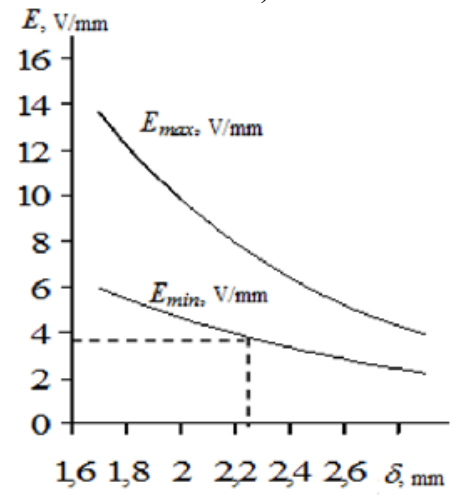

c)

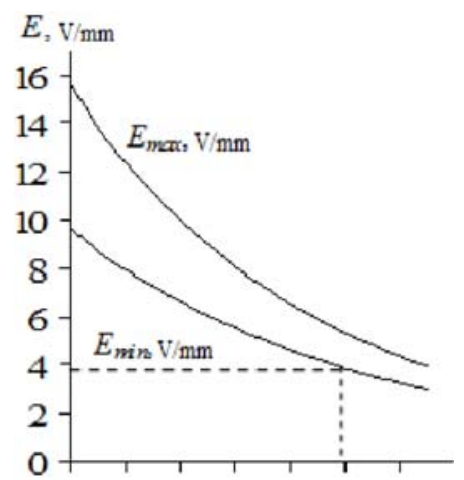

$1,61,8 \quad 2 \quad 2,22,42,6 \delta \mathrm{mm}$

b)

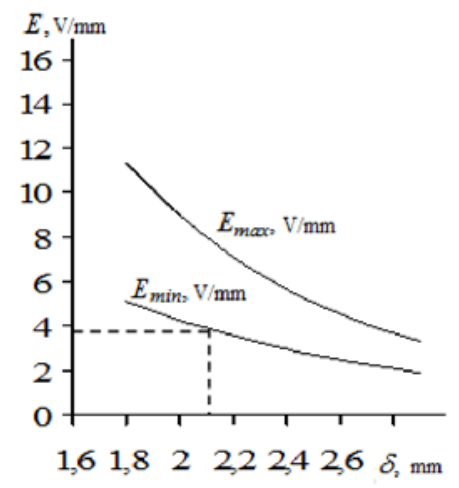

d)

Fig. 1. Dependences of maximum $E_{\max }$ and minimum $E_{\min }$ electric field strength on the thickness $\delta$ of the hardened paste layer at electrodes oscillations with amplitude $A=0.5 \mathrm{~mm}(\mathrm{a}, \mathrm{b})$ and frequency $f=$ $25 \mathrm{~Hz}$ (a) and $f=50 \mathrm{~Hz}$ (b) and with amplitude $A=1.1 \mathrm{~mm}$ (c, d) and frequency $f=25 \mathrm{~Hz}$ (c) and $f=$ $50 \mathrm{~Hz}(\mathrm{~d})$

Data analysis of fig. 1 shows that increasing the amplitude and frequency of oscillations of the carbon electrode leads to reducing the thickness of the hardened layer of the paste 
which is acceptable for stable arc combustion. In the range of amplitudes and frequencies of oscillations of the carbon electrode it corresponds to $\delta=2.1 \ldots 2.8 \mathrm{~mm}$.

In this case, one of the factors limiting the thickness of the hardened layer of the paste can be attributed to the stability of the arc ignition process, since the stable arc combustion is ensured even at high values of the thickness of the paste hardened layer. This is mainly due to the fact that during stable arc combustion its cross-section increases, approaching the cross-section of the carbon electrode, and resistance, respectively, decreases, which leads to a decrease in the electric field strength. Therefore, given the data presented in [12], the values $\delta=2.1 \ldots 2.5 \mathrm{~mm}$ can be referred to the most rational thickness of the hardened paste layer from the position of arc ignition and combustion.

\section{Results and discussion}

When testing the theoretical modeling results, which ensure stable combustion of electric arc during the CVAH, the following was established. When a $2.1 \ldots 2.5 \mathrm{~mm}$ thick layer of the multicomponent paste is created on the hardened surface, the electric arc ignites and burns steadily, which leads to the formation of a high integrity and quality metal-ceramic coating (fig. 2, a). If the thickness of the paste layer increases to $2.8 \ldots 3.0 \mathrm{~mm}$, the electric arc burns very unstable and a uniform high-quality metal-ceramic cover is absent in this case (fig. 2, b). Increasing the thickness of the passive layer over $3.0 \mathrm{~mm}$ makes it impossible to ignite the electric arc.

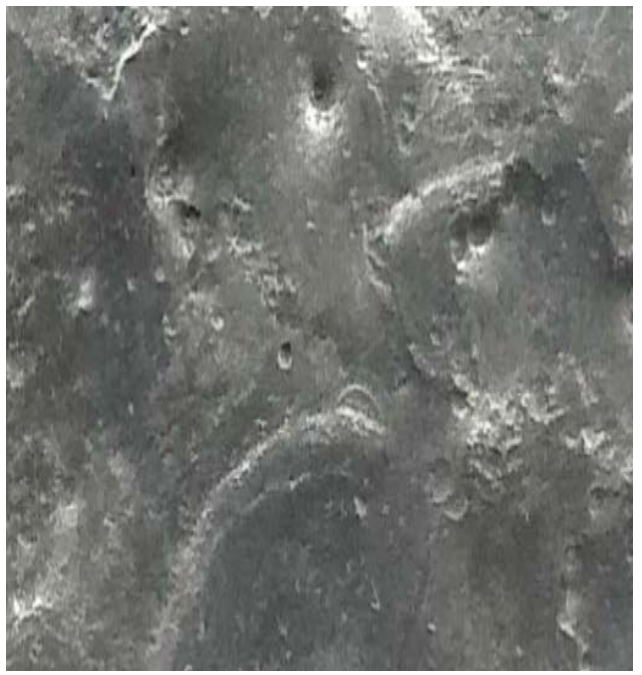

a)

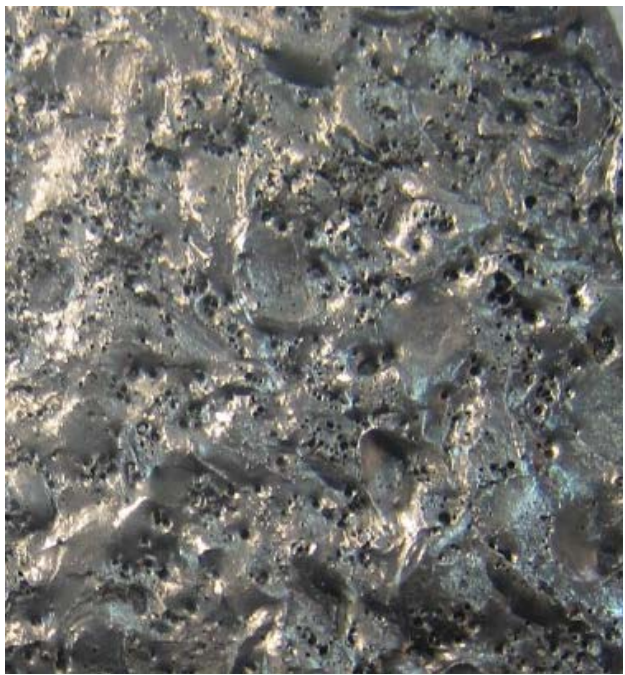

b)

Fig. 2 - High-quality metal-ceramic coating with high integrity (a), formed with a layer thickness of the multicomponent paste $2.4 \mathrm{~mm}$, and low-quality coating (b), formed with a layer thickness of paste $2.9 \mathrm{~mm}$

\section{Conclusions}

Theoretical regularities of electric field intensity formation by oscillating carbon electrode during the CVAH (carbo-vibro-arc hardening) have been established. The maximum thickness of the multicomponent paste layer of $2.1 \ldots 2.5 \mathrm{~mm}$, which ensures stable electric arc combustion at the CVAH, has been theoretically substantiated. It is established that with increasing amplitude and frequency of oscillations of the carbon electrode the electric field 
intensity at the CVAH decreases nonlinearly, however, the thickness of the hardened layer of the multicomponent paste has the greatest influence on its value. The testing of the obtained theoretical regularities confirmed their reliability.

\section{References}

1. V.P. Lyalyakin, V.P. Murzaev, R.Y. Solovev, D.B. Slinko, Physico-mechanical properties of coatings produced by electric arc metalizing with flux-cored wires. Welding International, v. 31, № 9, pp. 729-732 (2017)

2. A.M. Stolin, P.M. Bazhin, M.V. Mikheev et al. Protective coating application by arc surfacing with SHS electrodes, Welding International, №8. pp. 52-56 (2014)

3. S.N. Sharifullin, N.R. Adigamov, N.N. Adigamov, R.Y. Solovev, K.S. Arakcheeva Surface hardening of cutting elements agricultural machinery vibro arc plasma. Journal of Physics: Conference Series, v. 669, № 1, pp. 012049 (2016)

4. A.A. Golyshev, A.M. Orishich, A.A. Filippov, Formation of B4C - Ti-6AL-4V metalceramic coatings by SLM method, Metal Science and Heat Treatment, № 11 (785), pp. 39-43 (2020)

5. V.M. Fomin, A.A. Golyshev, V.F. Kosarev et al. Creation of Metal-Ceramic Structures Based on Ti, Ni, WC and B4C Using Laser Surface Coating and Cold GasDynamic Spraying Technologies, Physical Mesomechanics, V. 22, № 4, pp. 5-15 (2019)

6. N.A. Rudenskaya, G.P. Shveykin, V.A. Guletsky, Hardening effects of metal-ceramic coatings during their formation, Doklady Akademii nauk, V. 433, № 6, pp. 776-779 (2010)

7. Y.P. Lobachevsky, S.A. Sidorov, D.A. Mironov et al. New wear-resistant surfacing materials in agricultural engineering, Agricultural machinery and technology, № 6, pp. 27-31 (2014)

8. N.V. Titov, A.V. Kolomeichenko, V.N. Logachev, I.N. Kravchenko, N.N. Litovchenko, Investigation of the hardness and wear resistance of working sections of machines hardened by vibroarc surfacing using cermet materials. Welding International, V. 29, № 9, pp. 737-739 (2015)

9. V.V. Vinogradov, Increasing the wear resistance of A-shares of soil tillage implements by carbo-vibro-arc hardening of their cutting surfaces, Abstract of thesis of Candidate of Technical Sciences. ... candidate of technical sciences. 05.20.03. Voronezh, $16 \mathrm{p}$. (2017)

10. A.A. Sharafiev, M.N. Adigamova, N.R. Adigamov, Influence of metal-ceramic compositions on the surface of hardened working tools. Modern Status, Problems and Prospects of Mechanization and Technical Service of Agroindustrial Complex: Proceedings of the International Scientific-Practical Conference of the Institute of Mechanization and Technical Service. Kazan: Publishing house of Kazan GAU, pp. 239-242 (2018)

11. N.V. Titov, A.V. Kolomeichenko, Technology of Reconditioning with Hardening of Working Elements of Construction and Road Machines by Composite Coatings

12. N.V. Titov, A.V. Kolomeichenko, V.L. Basinyuk et al. Theoretical bases of formation of qualitative metal-ceramic coatings under carbo-vibro-arc hardening, Metal Technology, №6, pp. 2-11 (2020) 
13. S.N. Sharifullin, N.R. Adigamov, E.Yu. Kudryashova, Tribological Researches of Surfaces of Parts from Steel 65G, Plasma-Hardened Methods. Tekhnicheskiy servis mashin, № 3 (136), pp. 120-127 (2019)

14. A.V. Kolomeychenko, N.V. Titov, V.V. Vinogradov, A.M. Stolin, P.M. Bazin, The microstructure of composite cermet coatings produced by carbo-vibroarc surfacing. Welding International, V. 31, №. 9, pp. 739-742 (2017)

15. V.M. Nerovny, A.V. Konovalov, B.F. Yakushin et al. Theory of welding processes, textbook for universities, 702 p. (2016) 